\title{
Elucidating the mechanism of cellular uptake of fullerene nanoparticles
}

\author{
Yeonjeong $\mathrm{Ha}^{{ }^{\dagger}}$, Xianzhe Wang ${ }^{2}$, Howard M. Liljestrand ${ }^{1}$, Jennifer A. Maynard ${ }^{3}$, Lynn E. Katz ${ }^{1}$ \\ ${ }^{1}$ Department of Civil, Architectural and Environmental Engineering, The University of Texas at Austin, Austin, Texas 78712, United States \\ ${ }^{2}$ Department of Biochemistry, The University of Texas at Austin, Austin, Texas 78712, United States \\ ${ }^{3}$ Department of Chemical Engineering, The University of Texas at Austin, Austin, Texas 78712, United States
}

\begin{abstract}
Understanding the molecular interactions between biological cells and engineered nanoparticles is a key to evaluating potential toxicities to humans and the environment. This study developed a method to determine the mechanisms by which fullerene aggregates are distributed into a representative cell line, human intestinal Caco-2 cells. First, we determined that the presence of fetal bovine serum (FBS) in the cell culture media changes the particle characteristics and inhibits particle adsorptions onto cell surfaces. Second, significantly lower amounts of fullerene were internalized at $4^{\circ} \mathrm{C}$, a temperature at which active transport mechanisms are effectively impeded, than at $37^{\circ} \mathrm{C}$. Third, metabolic inhibitors of active transport and a microtubule transport inhibitor decreased fullerene uptake at $37^{\circ} \mathrm{C}$. Fourth, cellular uptake of fullerene increased with increasing fullerene concentration, suggesting that passive diffusion into lipid membranes contributed to uptake over the broad concentration range used in this study. Together, these results indicate fullerene transport into cells occurs via two mechanisms: passive diffusion across the lipid bilayer and active transport including microtubule involved endocytosis. The results also suggest that simple physical-chemical partitioning models do not fully describe fullerene uptake, and instead, active transport models are also required to estimate the cellular uptake and toxicity of fullerene.
\end{abstract}

Keywords: Cellular uptake, Endocytosis, Fullerene, Passive diffusion

\section{Introduction}

As the production of engineered nanoparticles rapidly increases, concerns of the potential unknown harmful effects of these nanomaterials towards humans and the environment have grown. Promising applications of nanomaterials in the biomedical field include use as drug carriers [1,2] and for gene delivery [3]. In these applications and others, engineered nanoparticles come into contact with living tissues in various organisms, including humans. Due to their nano-size, it has been reported that, nanoparticles easily enter cells [4-6] and cause toxic effects. Thus, assessing the mechanisms mediating the cellular uptake of nanoparticles is essential to understanding their biological fate as well as potential harmful effects.

Cellular membranes serve as biological barriers and restrict internalization of nanoparticles. Recently, the cellular uptake mechanism of engineered nanoparticles has been reported to differ from that of dissolved solutes. Small hydrophobic molecules are known to pass through the cellular membrane via passive transport driven by concentration gradients. However, recent studies also have indicated that nanoparticles, including those made from transferrin-coated gold [7], amorphous silica [8], and carbon nanotubes [9], can enter cells through endocytosis, which is an energy-dependent active process.

Carbon fullerene $\left(\mathrm{C}_{60}\right)$ has emerged as a particularly useful type of nanoparticle; however, it is cytotoxic due to lipid peroxidation $[10,11]$. Previous studies have indicated that fullerene dispersions exhibit toxicity toward bacteria [12], human cell lines [10], and aquatic organisms [13]. Fullerene toxicity mechanisms are still not well understood, and little is known about the mechanisms of cellular uptake of fullerene due to the difficulties related with quantitative measurement of these particles in cells. Previous studies used visualization techniques such as transmission electron microscopy to locate intracellular fullerene and its derivatives [11,
This is an Open Access article distributed under the terms of the Creative Commons Attribution Non-Commercial License (http://creativecommons.org/licenses/by-nc/3.0/) which permits unrestricted non-commercial use, distribution, and reproduction in any medium, provided the original work is properly cited.

Copyright (C) 2022 Korean Society of Environmental Engineers
Received November 26, 2020 Accepted February 28, 2021

${ }^{\dagger}$ Corresponding author

E-mail: gbhyjyh@korea.ac.kr

Tel: +82-10-3108-1521

ORCID: 0000-0001-5637-3891 
14-16]. In addition, several studies used fluorescent or radioactive labels to easily quantify the fullerene nanoparticles from the cell culture medium [17, 18]. However, the labeled nanoparticles, as more water soluble derivatives, differ from unmodified fullerene aqueous suspensions and may exhibit different cellular uptake mechanisms and toxicities as compared with fullerene nanoparticles [19].

Moreover, most previous studies did not explore the cellular mechanisms mediating fullerene uptake. To our knowledge, few qualitative studies have reported the cellular uptake of fullerene derivatives. $\mathrm{Li}$ et al. [20] reported that active transport can internalize malonic acid derivatized fullerene $\left(\mathrm{C}_{60}\left(\mathrm{C}(\mathrm{COOH})_{2}\right)_{3}\right)$ into cells. In addition, it was confirmed that the fluorescent labeled $\mathrm{C}_{60}$ appeared inside the plasma membrane by taking the confocal fluorescence images [21]. However, these fullerene derivatives might be more hydrophilic than unmodified fullerene dispersions [20], and its biological impacts are different from unmodified fullerene. Thus, it is essential to develop a quantitative method to evaluate the cellular uptake mechanism of unmodified fullerene dispersions in water.

Here, a quantitative assay to assess the uptake of unmodified fullerene into cells was developed and used the assay to assess the relative roles of passive and active uptake. Human Caco-2 cells were selected as they are derived from a human colorectal adenocarcinoma and show functional and morphological characteristics similar to that of the epithelium of the small intestines [22]. Caco-2 cell monolayers have been used to determine the membrane permeability of drugs and small molecules. In addition, unlike other in-vitro models (e.g., parallel artificial membrane permeation assay (PAMPA)) that can only be applied for passive transport, Caco-2 cells have been used to investigate both active transport and passive diffusion [23-26]. Also, previous studies suggested that the main membrane transport mechanism of nanoparticles is a cellular endocytotic process using Caco-2 cells [27-30]. Thus, the in-vitro model applying Caco-2 cells is considered an appropriate model for investigating the cellular uptake mechanisms of fullerene.

In this work, a quantitative in-vitro method for cellular uptake of fullerene with undifferentiated Caco- 2 cells was developed that uses a modified liquid-extraction method to extract fullerene from cell culture medium and cell lysate [19, 31, 32]. The application of our novel assay was the identification of the mechanisms of fullerene cellular uptake. First, we investigated the effects of protein presence on the fullerene characteristics and their cellular uptake. Also, we used low temperature and metabolic inhibitors to prohibit active transport mechanisms, allowing us to minimize the effects of passive transport. Lastly, since active transport can be saturated by high concentrations, we varied the fullerene concentration.

\section{Experimental Sections}

\subsection{Preparation of Fullerene Nanoparticles}

Fullerene $\left(\mathrm{C}_{60}, 99.5+\%\right)$ purchased from SES Research (Houston, TX, USA) was used to make aqueous dispersions prepared by the method reported in Brant et al. [33] and modified as described in our previous studies [34, 35]. Briefly, solid fullerenes were dissolved in toluene and then dispersed in deionized water. Next, the toluene was removed by ultrasonication for $4-5 \mathrm{~h}$ with air-purging, yielding aqueous yellowish fullerene nanoparticles. A $0.8 \mu \mathrm{m}$ membrane filter (Millipore) was used to remove large aggregations in the resultant fullerene dispersions. Final fullerene dispersions were stored at $4^{\circ} \mathrm{C}$ and applied to the cellular tests within $2 \mathrm{~d}$ of preparation to minimize changes in particle characteristics. The average size and zeta potential of fullerene measured by Dynamic Light Scattering (DLS, Malvern Zetasizer Nano ZS)range from 120 to $130 \mathrm{~nm}$ and from -35 to $-50 \mathrm{mV}$, respectively, and Transmission Electron Microscopy (TEM, FEI Tecnai) imaging shows that the shape of the particles is spherical (Fig. 1(a)). For liquid extraction of fullerene from the cell culture medium and cellular lysate over the concentration range used in this study, fullerene was serially diluted into water, serum-free medium, or cellular lysate to final concentrations of $0.17,0.33,0.49$, and $0.66 \mathrm{mg} \mathrm{L}^{-1}$, respectively. The recovery of fullerene from each solution was determined after liquid extraction (The liquid extraction method is described in Section 2.3.) For the experiment using inhibitors, to specify the uptake mechanism of fullerene dispersions over time, preliminary experiments performed to characterize changes in fullerene aggregation state in the inhibitors free condition. Fullerene aggregates incubated in deionized water were examined over $14 \mathrm{~d}$, and the particle size and zeta potential were measured by DLS to quantify changes in the fullerene aggregates in over time. For every sampling event, fullerene preparations were filtered using a $0.8 \mu \mathrm{m}$ membrane filter to remove any large aggregates that would settle down rapidly during the test. Finally, to assess the effect of the concentration of nanoparticles on cellular uptake, fullerene aggregates were prepared at two different concentrations. After preparing the low stock solution $\left(\sim 20 \mathrm{mg} \mathrm{L}^{-1}\right)$, the high stock solution $\left(120 \mathrm{mg} \mathrm{L}^{-1}\right)$ was prepared by concentrating the low stock solution via water evaporation. Then, different dilutions of fullerene were prepared from each stock. Each solution was then diluted 10-fold in the cell culture medium, resulting in concentration ranges of 1-2 mg $\mathrm{L}^{-1}$ and 3-12 $\mathrm{mg} \mathrm{L}^{-1}$ for low and high concentrations, respectively.

\subsection{Cell Culture}

The Caco-2 cell was purchased from American Type Culture Collection (ATCC). The culturing procedure for the Caco-2 cells was as described in previous research [22, 23]. In brief, Caco-2 cells were maintained under an atmosphere of $5 \% \mathrm{CO}_{2}$ in flasks of Dulbecco's modified Eagle medium (D-MEM) containing $0.1 \mathrm{mM}$ nonessential amino acids, penicillin/streptomycin (100 $\left.\mathrm{U} \mathrm{mL}^{-1}\right)$, $10 \% \mathrm{FBS}$, and $4 \mathrm{mM} \mathrm{L-glutamine.} \mathrm{The} \mathrm{cells} \mathrm{were} \mathrm{transferred} \mathrm{to}$ tissue culture flasks until they reached confluence, and cell monolayers were incubated with EDTA solution and trypsin. Cells underwent at least two passages before being used for cellular uptake assays and were not used past passage 10 .

\subsection{Cellular Uptake Experiment}

For the cellular uptake experiments, Caco-2 cells were first washed with phosphate buffer solution (PBS) several times and then detached using trypsin-EDTA solution. The cells were transferred into 6-well polycarbonate plates at a seeding density of $10^{5}$ cells 
$\mathrm{cm}^{-2}$, followed by incubating at $37^{\circ} \mathrm{C}$ in $5 \% \mathrm{CO}_{2}$. After two days, media was replaced with 10 -fold diluted fullerene in serum free medium and incubated for $24 \mathrm{~h}$. Each uptake test was finished by washing cells with PBS for removing free particles. Then, using $400 \mu \mathrm{L}$ trypsin-EDTA solution, the cells were detached and collected from the plates, transferred into glass vials, and lysed via ultrasonication for $30 \mathrm{~min}$. Fullerene was extracted from the cells in trypsin to $1 \mathrm{~mL}$ toluene through liquid extraction. For liquid extraction, $0.1 \mathrm{M} \mathrm{Mg}\left(\mathrm{ClO}_{4}\right)_{2}(400 \mu \mathrm{L})$ and glacial acetic acid $(2.5 \mathrm{~mL})$ were first added to samples containing fullerene followed by 1 $\mathrm{mL}$ toluene and vigorous shaking. Fullerene concentrations in toluene were measured using a Waters 2690 high-performance liquid chromatography (HPLC) system together with a Waters 996 photodiode array detector at $328.6 \mathrm{~nm}$.

To specify the cellular uptake mechanism, cells were preincubated with individual metabolic inhibitors, sodium azide (1.2 $\mathrm{mM})$, 2,4-dinitrophenol ( $0.17 \mathrm{mM})$, or a microtubule transport inhibitor, nocodazole $(6.35 \mu \mathrm{M})$, for $20 \mathrm{~min}$. Trypan blue exclusion (Strober 2001) determined that $>95 \%$ of cells were viable $24 \mathrm{~h}$ after inhibitors were added. (Table 1). After 20 minutes of pre-incubation with inhibitors, $200 \mu \mathrm{L}$ of fullerene suspensions in water were added into each well containing $1.8 \mathrm{~mL}$ of cell culture medium with an inhibitor and incubated for $24 \mathrm{~h}$. For experiments performed at $4^{\circ} \mathrm{C}$, cells and fullerene in cell culture medium were pre-incubated at $4^{\circ} \mathrm{C}$ for at least $30 \mathrm{~min}$ prior to the addition of nanoparticle dispersions.

\section{Results and Discussion}

To develop a quantitative assay to assess the cellular uptake of fullerene, the liquid extraction recovery ratio of fullerene was determined. Then, fullerene transport mechanisms were evaluated by assessing the effects of the FBS in cell culture media and by investigating the temperature and concentration dependence of cellular uptake and the effects of active transport inhibitors on the cellular uptake.

\subsection{Developing a Quantitative Method to Assess the Cellular Uptake of Fullerene}

As shown in Fig. S1, the HPLC peak areas showed good correlation with actual fullerene concentrations. The recovery ratios varied with the different media, resulting in different slopes for the standards' the linear regression best fits. The mean liquid extraction recovery ratios from cell culture media which were exposed to Caco-2 cells and cell lysates were $61 \pm 7.63 \%$ and $32 \pm 1.34 \%$, using 4 and 3 samples, as shown in Fig. S1, respectively. These recovery ratios were used to calculate the actual fullerene concentration extracted from different samples.

By applying these recovery ratios, we also checked the mass of fullerene nanoparticles recovered from cell lysates, cell culture medium, and buffer (Fig. S2). While the fullerene was cell associated, some nanoparticles also remained in the cell culture medium and some was recovered from the PBS used in the cell wash. As shown in Fig. S2, the estimated total mass recovered from each sample reached $74-98 \%$ using triplicate independent samples.

In this study, we used undifferentiated Caco-2 cells, and previous studies have reported that cellular uptake in undifferentiated cells may differ from uptake in differentiated cells [36, 37].

\subsection{Effects of the Presence of Protein in Cell Culture Medium}

To investigate the effects of the presence of protein on the characteristics of fullerene nanoparticles, particle shape and size were detected after incubation of fullerene for $24 \mathrm{~h}$ in the presence and absence of $10 \%$ FBS in cell culture medium (Fig. 1). As mentioned above, fullerene dispersions in water have average size of 120-130 $\mathrm{nm}$ and spherical shape (Fig. 1(a)). As shown in Fig. 1(b), the TEM image shows that the size of individual fullerene nanoparticles incubated in the cell culture medium without FBS significantly decreased although fullerene aggregation size was not changed. In contrast, in the presence of FBS in cell culture medium, fullerene aggregation shape was uniformly spherical (Fig. 1(c)), possibly due to the protein adsorption on the surface of fullerene aggregation. In our previous study [35], we investigated the effects of FBS on the size distributions of the fullerene nanoparticles, and showed that with $10 \%$ FBS, the fullerene size distribution shifted to slightly higher mean particle size and became narrower, possibly due to the FBS adsorption on the particle surfaces.

The rate of fullerene uptake was investigated to determine whether cellular uptake exhibits saturation kinetics. Two different cell cul-

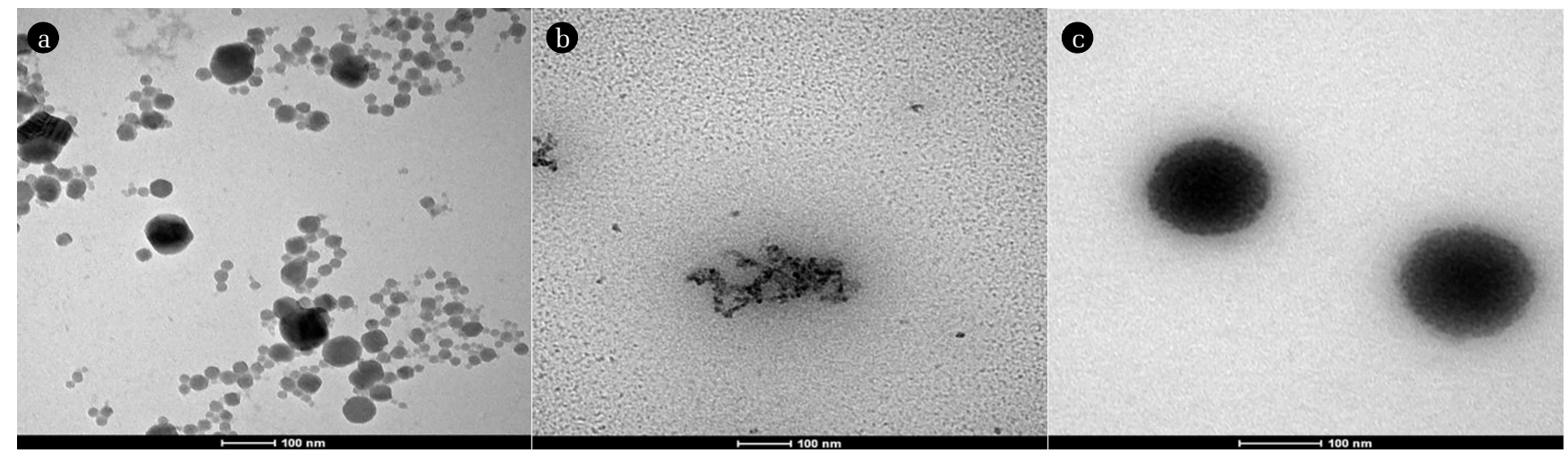

Fig. 1. TEM images of fullerene dispersions in (a) deionized water, (b) cell culture medium without FBS, and (c) cell culture medium in the presence of $10 \%$ FBS. 
ture media were prepared: one containing 10\% FBS, and a serum-free media without FBS. Caco-2 cells with and without FBS were incubated at $37^{\circ} \mathrm{C}$ with fullerene suspensions $\left(\mathrm{C}_{0}=0.8 \mathrm{mg} \mathrm{L}^{-1}\right)$ for up to $24 \mathrm{~h}$. Then, fullerene particles remaining in the media were transferred and extracted for HPLC analysis. As shown in Fig. 2(a), fullerene concentrations in the media with FBS did not decrease until $24 \mathrm{~h}$. On the other hand, fullerene concentrations in serum-free medium decreased continuously, reaching a steady state value within $12 \mathrm{~h}$. In addition, our previous research showed that FBS, which contains various proteins, effectively suppressed fullerene aggregation [35]. Thus, results presented in Fig. 2(a) suggest that protein adsorption onto surfaces of fullerene particles with FBS reduces the efficiency of cellular uptake as compared with unmodified fullerene suspensions in serum-free conditions.

For all other experiments in this study, we examined uptake of fullerene suspensions using serum-free cell culture medium. As shown in Fig. 2(b), the mass taken up by cells increased with time, reaching a plateau within $12 \mathrm{~h}$. Therefore, $24 \mathrm{~h}$ was selected for routine experimentation. Experiments examining uptake in FBS-free medium showed a similar fullerene distribution pattern (Fig. S2).

Fig. 3 shows a schematic illustration of plausible mechanisms of fullerene uptake by cells in the presence of FBS (Fig. 3(a)), and under FBS free condition (Fig. 3(b)). In the presence FBS, fullerene nanoparticles were effectively coated by FBS, which minimizes the surface energy, resulting in no adsorption on the cell surface. Recent studies also have reported that protein inhibits cellular uptake of nanoparticles such as silver [38] and silica nanoparticles [39]. On the other hand, under FBS-free condition, fullerene aggregations might partially disaggregate when they approach on the cell surface, possibly due to the hydrophobic interactions between nanoparticles and acyl chains of lipid bilayers. These small clusters can transport cell membranes via passive diffusion as well
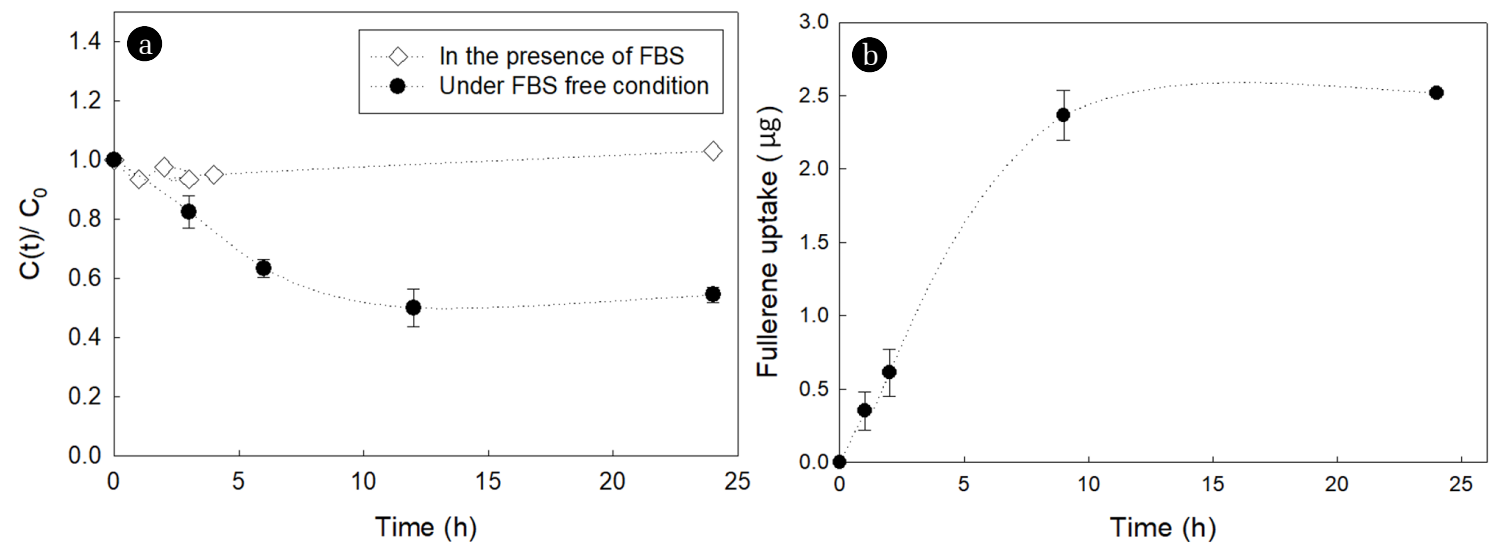

Fig. 2. Cellular uptake kinetics of fullerene nanoparticles. (a) Kinetics of fullerene nanoparticle $\left(C_{0}=0.8 \mathrm{mg} \mathrm{L}^{-1}\right)$ removal in cell culture media in the presence of FBS and serum free media. $\mathrm{C}(\mathrm{t})$ represents the fullerene concentration remaining in cell culture media after time $t$. (b) Kinetics of cellular uptake of fullerene nanoparticles $\left(\mathrm{C}_{0}=4.1 \mathrm{mg} \mathrm{L}^{-1}\right.$; initial mass $\left.=8.2 \mu \mathrm{g}\right)$ at $37^{\circ} \mathrm{C}$. Using three replicates, the average \pm standard $(\mu \mathrm{g})$ deviation were $0.35 \pm 0.13,0.61 \pm 0.16$, and $2.37 \pm 0.17$ for 1,2, and $9 \mathrm{~h}$, respectively, For $24 \mathrm{~h}$, and the average value was $2.52 \mu \mathrm{g}$ using two replicates.
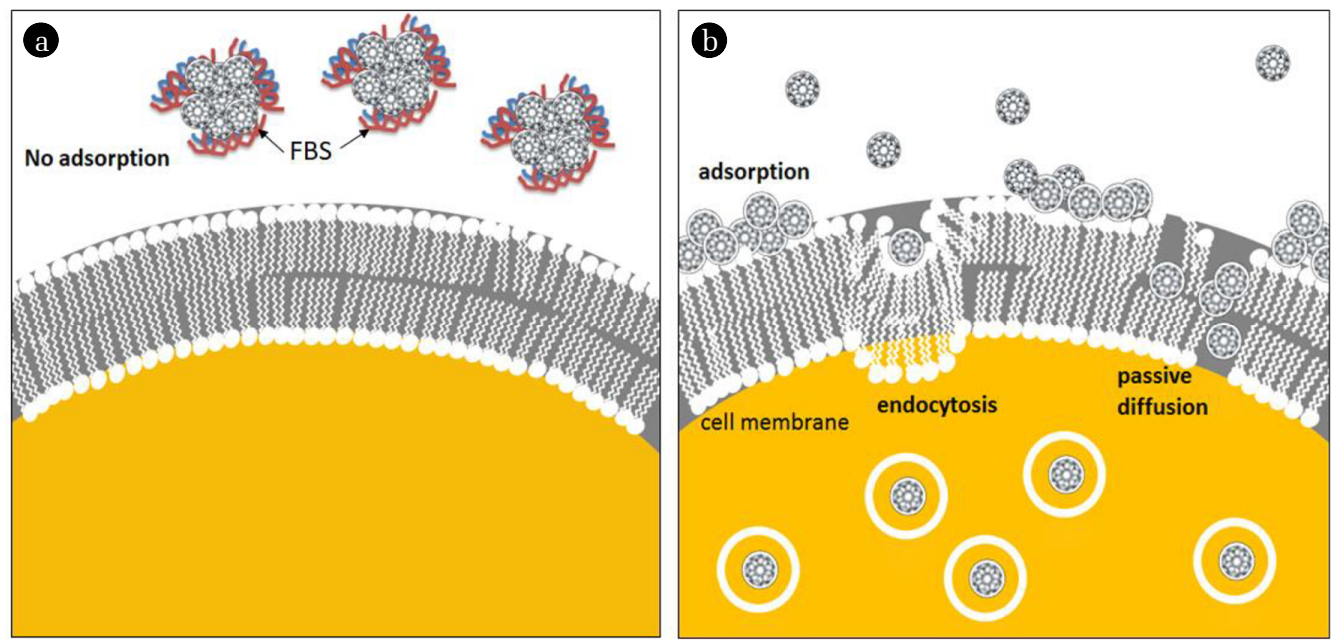

Fig. 3. Schematic illustration of possible mechanisms of cellular uptake of fullerene (a) in the presence of FBS and (b) under FBS-free condition. 
as active transport. More details on the cellular uptake mechanism under serum-free condition are described in a later section.

\subsection{Temperature Dependence on Cellular Uptake}

The effect of temperature on fullerene uptake by Caco-2 cells was investigated (Fig. 4). As shown in Fig. 4(a), decreasing the temperature from $37^{\circ} \mathrm{C}$ to $4^{\circ} \mathrm{C}$ reduced the cellular uptake of fullerene by $38-54 \%$ from triplicate samples for incubation times from 1.5 $\mathrm{h}$ to $4 \mathrm{~h}$. Similar trends in temperature dependence have been observed with other nanomaterials such as polymeric nanoparticles [27], gold nanoparticles [7], and chitosan-insulin nanocomplexes [28]. For gold and chitosan-insulin nanoparticles, it was reported that cellular uptake was reduced by approximately $70 \%$ by decreasing the temperature from $37^{\circ} \mathrm{C}$ to $4^{\circ} \mathrm{C}$. At $4^{\circ} \mathrm{C}$, several active transport processes are unable to function [40]; thus only adhesion and passive diffusion processes will be operative under these conditions. In contrast, at $37^{\circ} \mathrm{C}$, both passive and active transports are operative; once fullerene particles attach to the cell surface, they can diffuse through the lipid membranes or translocate via endocytotic active transport such as receptor-mediated endocytosis. Therefore, active transport might be partly responsible for the significant increase in mass of fullerene taken by the cells at higher temperatures.

Fig. 3(b) illustrates the possible fullerene cellular uptake mechanisms at $37^{\circ} \mathrm{C}$. Two steps associated with fullerene cellular uptake are postulated: 1) physical adsorption to the cell surface, followed by 2) internalization by passive diffusion across the cellular membrane or an energy-dependent process. At $37^{\circ} \mathrm{C}$, fullerene first adsorbs on the cell surface due to the electrostatic interactions [34, 41]. Because both the surface charges of the cells and fullerene nanoparticles in water are negative, there is at best a weak affinity between the particles and cell surface. However, a previous study [42] indicated that SK-BR-3 breast cancer cell have positively charged sites which can allow negatively charged particles to adhere to the cell surface. The mass fluxes at two different temperatures are calculated. The mass fluxes are $0.312 \pm 0.05\left(\mu \mathrm{g} \mathrm{h}^{-1}\right)$ at $4^{\circ} \mathrm{C}$ and $0.583 \pm 0.08\left(\mu \mathrm{g} \mathrm{h}{ }^{-1}\right)$ at $37^{\circ} \mathrm{C}$,

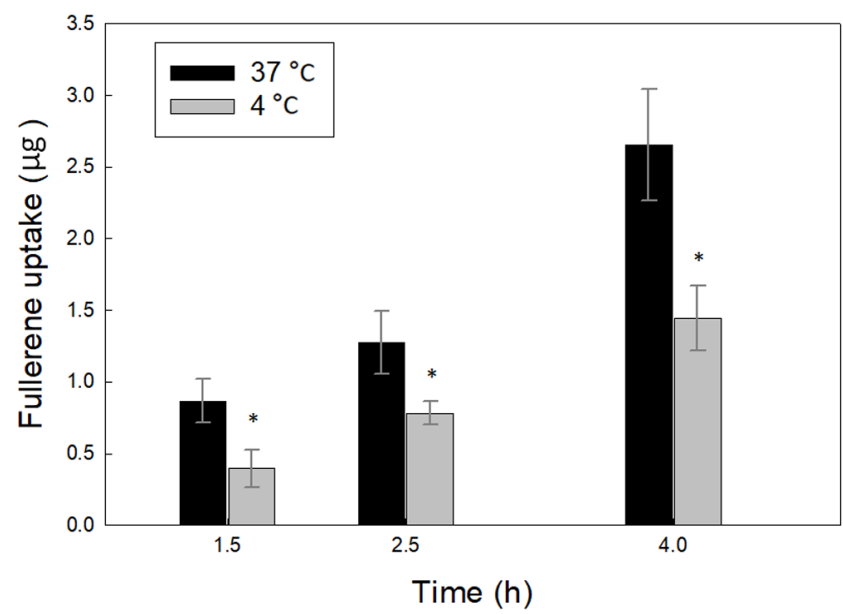

Fig. 4. Temperature dependence on the cellular uptake of fullerene nanoparticles into Caco-2 cells in serum-free media $\left(C_{0}=4.7\right.$ $\mathrm{mg} \mathrm{L^{-1 }}$ ). *denotes that fullerene uptake mass at $4^{\circ} \mathrm{C}$ is significantly lower than the values at $37^{\circ} \mathrm{C}(p<0.05$ using student's t-test). The error bars represents standard deviations of triplicate analyses. which indicate that the internalization step through active transport (e.g., endocytosis) at $37^{\circ} \mathrm{C}$ was faster than adsorption/passive diffusion at $4^{\circ} \mathrm{C}$. Previous studies of cellular uptake of iron nanoparticles [43] and gold [42] have also demonstrated that the adherence process was much slower than the internalization step. Cho et al. [42] reported that the characteristic time $(\tau)$ for the overall cellular uptake process of gold nanoparticles was 3-12 times higher than those of the internalization step. Therefore, the adsorption step is the rate-determining process critically affecting the overall rate of uptake as well as the intracellular number concentration of nanoparticles.

\subsection{Effect of Endocytosis Inhibitors}

To investigate the effect of endocytosis inhibitors on the cellular uptake of fullerene, cells were pre-incubated with three inhibitors — sodium azide, 2,4-dinitrophenol, and nocodazole - prior to the addition of fullerene. Sodium azide and 2,4-dinitrophenol, as metabolic inhibitors, prevent energy production in cells. Thus, cells preincubated with sodium azide and 2,4-dinitrophenol are unable to transport nanoparticles via energy dependent endocytosis transport. Similarly, nocodazole inhibits microtubules involved in caveolae-mediated endocytosis or micropinocytosis.

These inhibitors must be used at sub-cytotoxic concentrations, a value which varies with cell type and exposure time. To confirm that our selected concentrations were sub-lethal, we incubated cells with each inhibitor at concentrations used in this study for $24 \mathrm{~h}$ and confirmed that the cells remained > 95\% viable (Table 1).

The size distribution of fullerene aggregates did not change significantly over up to $14 \mathrm{~d}$ (Fig. 5(a)); however, the zeta potential decreased continuously. Zeta potentials of fullerene samples initially, after $7 \mathrm{~d}$, and after $14 \mathrm{~d}$ were $-31.13 \pm 0.58,-28.17 \pm 0.58$, and $-19.37 \pm 0.38$ from three samples, respectively (Fig. 5(b)). These changes in the fullerene dispersions are consistent with a previous study[44] that suggested variations in size and zeta potential of fullerene aggregates in deionized water over time. The surfaces of fullerene aggregates are highly negatively charged. Thus, electrostatic repulsion inhibits further aggregation, resulting in little change in the particle size distribution over time. The origin of the negative surface charge on aqueous fullerene aggregates is still under debate. The most commonly accepted hypothesis for charge acquisition is hydroxyl ions adsorptions due to donor-acceptor interactions between fullerene and water [33, 45]. Although the $\mathrm{pH}$ of fullerene solutions did not change significantly over two weeks ( $\mathrm{pH}$ of Day 0 and Day 14 was 7.8), the addition of $\mathrm{CO}_{2}$ from the atmosphere may slightly reduce the $\mathrm{OH}^{-}$concentration in the solution, and in turn, reduce the adsorption of $\mathrm{OH}^{-}$ions on the fullerene surface. This decrease in adsorption of $\mathrm{OH}^{-}$might be explained by the zeta-potential reduction of fullerene over time.

Table 1. Applied Concentrations of Inhibitors and Cell Viability after $24 \mathrm{~h}$ of Incubation with Each Inhibitor

\begin{tabular}{lccc}
\hline Inhibitor & $\begin{array}{c}\text { Sodium } \\
\text { azide }\end{array}$ & 2,4-dinitrophenol & Nocodazole \\
\hline Concentration (mM) & 1.2 & 0.17 & $6.35 \times 10^{-3}$ \\
Cell viability (\%) & 95.5 & 98.4 & 96.0 \\
\hline
\end{tabular}



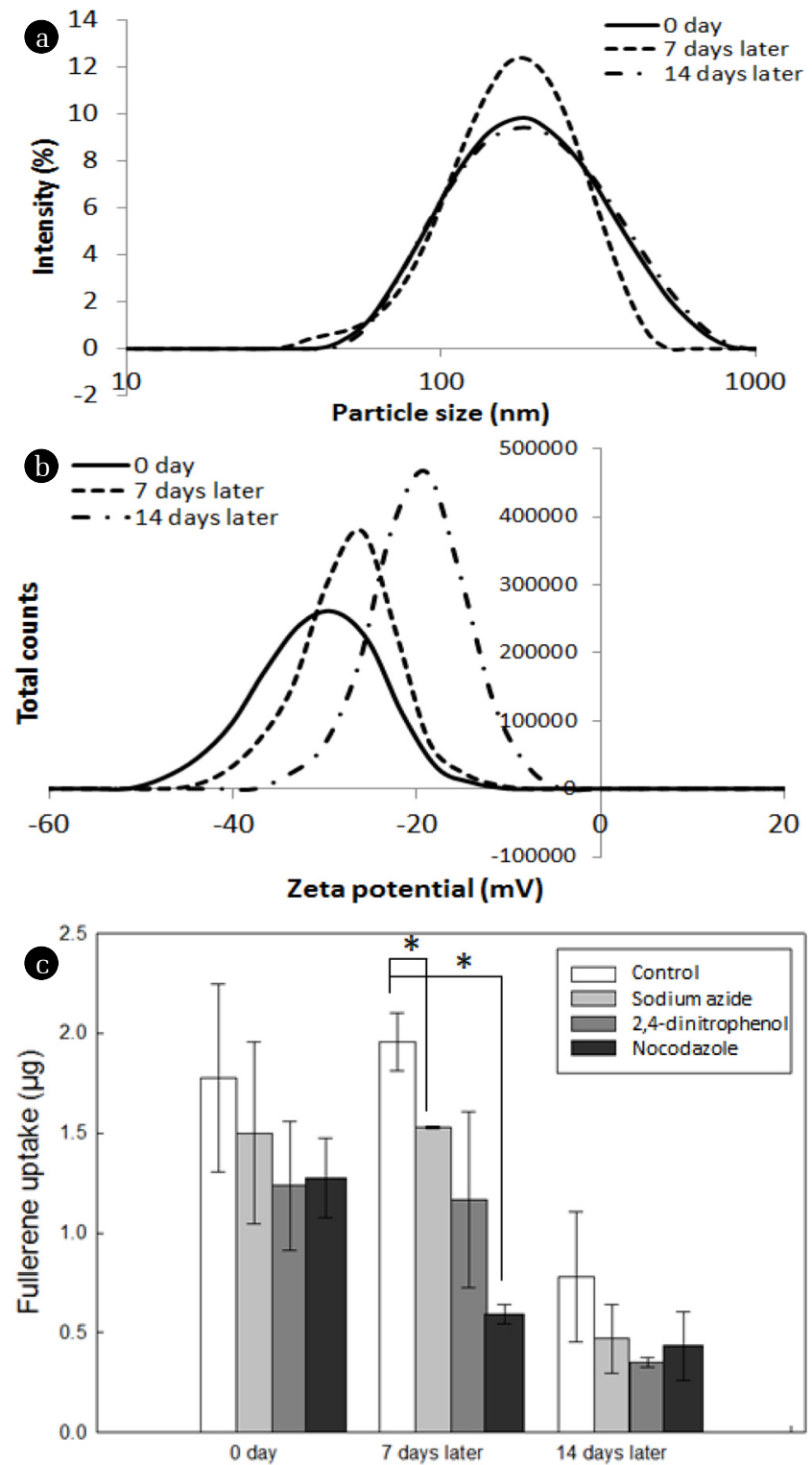

Fig. 5. Effects of endocytosis inhibitors on the cellular uptake of fullerene (a) Particle size and (b) zeta potential of fullerene nanoparticles incubating in deionized water as a function of incubation period. (c) Effect of inhibitors on fullerene uptake for varying fullerene incubation periods in deionized water. Sodium azide and 2,4 dinitrophenol are metabolic inhibitors, and nocodazole is a microtubule transport inhibitor. All inhibitors and cells were added $24 \mathrm{~h}$ prior to adding fullerene suspensions. Control group represents cells without inhibitor treatments. The error bars indicated standard deviations of triplicate analyses. *denotes that fullerene uptake after each inhibitor treatment is significantly lower than that without inhibitor $(p<0.05$ using student's $t$-test).

To examine the impact of the three inhibitors utilized in this study on the cellular uptake of fullerene, a two-way ANOVA test was conducted from the experiments in which fullerene added to cells which were pre-incubated with inhibitors at the initiation of incubation (Day 0) or after weeks of incubation (Day 7 and Day 14) (Supplementary Materials). The statistical analysis showed that the inhibitors significantly reduced the cellular uptake of fullerene at a $p$-value of 0.0008 , suggesting that active transport contributes to fullerene uptake. However, the cellular uptake in these experiments using initial concentrations of $2-3 \mathrm{mg} \mathrm{L}^{-1}$ of fullerene was not entirely inhibited in these systems, suggesting that passive transport may also contribute to fullerene uptake.

To define the statistical significance between the cellular uptake of control samples and samples with inhibitors at each fullerene incubation period, a student's $t$-test was used. As shown in Fig. 5(c), with fullerene pre-incubated for $7 \mathrm{~d}$ before the addition of metabolic inhibitors and cells, 2,4-dinitrophenol and sodium azide decreased fullerene uptake by the cells $(p<0.05$ ), indicating that energy-dependent endocytosis is key for fullerene cellular transport. However, when fullerene at the start of incubation (Day 0) was used, the presence of the inhibitors reduced the mean uptake, but the differences were not statistically significant $(p>0.05)$. No statistically significant difference was observed for the cellular uptake of fullerene with and without inhibitors using fullerene incubated for $14 \mathrm{~d}$ prior to the addition of inhibitors. While the lack of a statistically significant effect of the inhibitors at $14 \mathrm{~d}$ might be due to the changes in the surface charges, no explanation other than the relatively large standard deviation explains the lack of impact with the fullerene at the start of incubation (Day 0).

To provide additional data supporting a role for endocytosis in fullerene uptake, the microtubule inhibitor nocodazole was added to uptake assays. Microtubules are a cytoskeleton component, and microtubule transport of nanoparticles such as polystyrene nanoparticles [46, 47], polymer coated gold nanoparticles [48], and quantum dots [49-51] into cells has been reported. In addition, previous studies suggested that the inhibition of microtubule involved endocytosis was affected by particle size $[47,52]$ as well as particle surface charge [46, 48]. Again, when a two-way ANOVA test was conducted from all the data shown in Table S1 (Day 0, Day 7, and Day 14), nocodazole significantly reduced cellular uptake ( $p$ $=0.0009$ ) compared with control samples. Interestingly, one week after initiation of the incubation period (Day 7), and as the fullerene zeta potential decreased, nocodazole inhibited the transport of fullerene to a greater extent compared with that at the initiation of the incubation period (Day 0). Incubation for two weeks (Day 14) led to a significant reduction in both control samples and those containing inhibitors, which may be a result of the reduced interaction between positively charged cell surface groups and the negatively charged fullerene rather than due to changes in hydrophobicity of the fullerene. Nevertheless, the nocodazole had a significant impact on fullerene uptake after $14 \mathrm{~d}$ of fullerene/water incubation compared with the $14 \mathrm{~d}$ control. Thus, as fullerene became more hydrophobic over time, this change might have helped to promote transport through cell membranes via microtubule-dependent pathways such as macropinocytosis or caveolae-mediated endocytosis. Caveolae are hydrophobic membrane domains with mainly cholesterol and sphinogolipids, which can be involved in endocytosis pathways parallel to the clathrin-mediated endocytosis [53]. This result is consistent with a previous study [48] in which more hydrophobic polymer coated gold nanoparticles were found to have greater contributions from microtubule 
transport to cellular uptake compared with that of other hydrophilic nanoparticles.

\subsection{Concentration Dependence on Cellular Uptake}

Unlike passive diffusion, active transport involving receptors should have the property of saturation due to the limits number of membrane transport proteins on the cell surface. However, as shown in Fig. 6, uptake increased with concentration across both low and high concentration ranges, and did not show the property of saturation. This trend indicates passive diffusion is at least partially responsible for lipid membrane transport of fullerene because the concentration gradient across the lipid membranes is the primary driving force for passive diffusion transport.

Although the size of fullerene dispersions is much greater than the normal thickness of lipid bilayer (4-5 nm), previous simulation studies [54-56] reported that when fullerene aggregates approach the head group of lipid membranes, they tend to disaggregate into small particles and can diffuse into lipid membranes. In our previous study [41], we suggested that thermodynamic enthalpy $(\Delta \mathrm{H})$ and entropy changes $(\Delta S)$ of fullerene transport through lipid membranes are significantly higher compared with thermodynamic values of molecular level chemicals, which can be explained by diffusion of larger particles into lipid membranes.

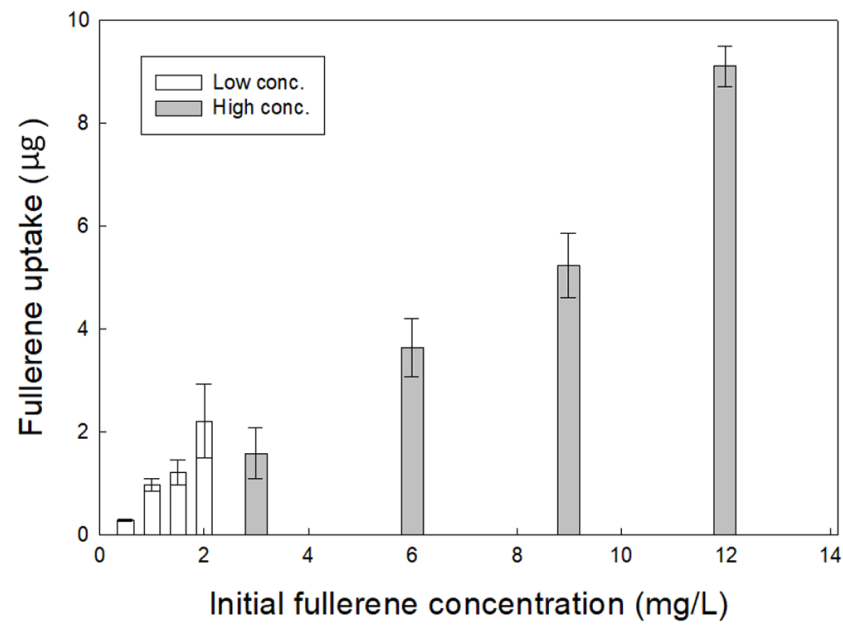

Fig. 6. The effec of concentration on the cellular uptake of fullerene nanoparticles at $37^{\circ} \mathrm{C}$. For low and high concnetrations, stock fullerene suspensions of $20 \mathrm{mg} \mathrm{L}^{-1}$ and $120 \mathrm{mg} \mathrm{L}^{-1}$ were prepared, respectively. Then, dilutions were prepared from each stock solution, ranging 0.5-2 $\mathrm{mg} \mathrm{L}^{-1}$, and 3-12 $\mathrm{mg} \mathrm{L}^{-1}$ for low and high concentration, respectively. The error bars indicate standard deviations of triplicate analyses.

\subsection{Environmental Implications}

The results of this study were compared with the reported values of fullerene accumulation in aquatic organisms $C_{\text {biomass }}[6,57-59]$ (Fig. 7). To calculate the $\mathrm{C}_{\text {biomass }}$ of fullerene, the mass of fullerene taken up by Caco-2 cells was divided by the dry Caco- 2 cell biomass. With cells growing in tissue culture plates at $\sim 10^{5}$ cells $\mathrm{cm}^{-2}$, the cell dry mass was $2.67 \pm 0.06 \mathrm{mg}$ from triplicate samples. The $\mathrm{C}_{\text {biomass }}$ values obtained from this study ranged between 103-4,552 $\mathrm{mg} \mathrm{kg}^{-1}$ which

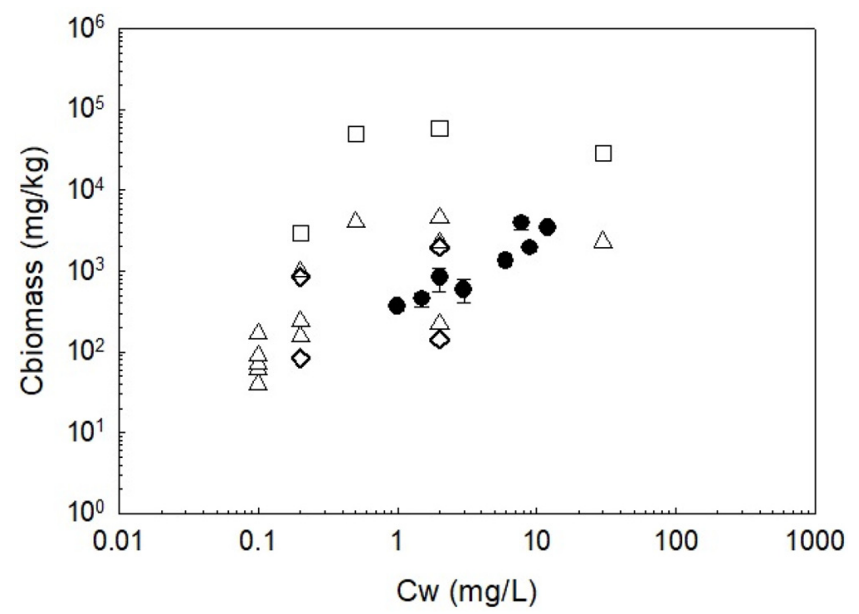

Fig. 7. Comparisons of concentrations of fullerene taken up by Caco-2 cells compared with reported bioaccumulation values for Daphnia and Danio (zebrafish) [6, 57-59]. Closed circles $(\bullet)$ fullerene uptake by cells (mass of fullerene per weight of dry cells; this work); open rectangles ( $\square$ ) and triangles $(\triangle)$ show the reported mass of fullerene that accumulates in the Daphnia normalized by dry and wet biomass weight, respectively. Open diamonds $(\diamond)$ are determined from the bioconcentration factor of fullerene taken up by Danio (zebrafish). For fullerene uptake by cells, the error bars indicate standard deviations of triplicate analyses (not shown when the error bars are smaller than the symbol).

are consistent with reported values of $\mathrm{C}_{\text {biomass }}$ for aquatic organisms (40-57,500 mg kg-1 for Daphnia and 152-222 mg kg-1 for Danio(zebrafish)). However, with a similar range of fullerene aqueous concentrations in water, $\mathrm{C}_{\text {biomass }}$ values for real aquatic organisms are higher than $\mathrm{C}_{\text {biomass }}$ values obtained from this study (Fig. 7), plausibly indicating that accumulation of fullerene into organs (e.g., intestine, gill, and gut) of real organisms, which have different surface ratios per mass, might be greater than those found for in vitro cell lines. Indeed, nanoparticles such as titanium dioxide $\left(\mathrm{TiO}_{2}\right)$, cadmium, and silver nanoparticles have been reported to be accumulated to a great extent into fish intestines and gills [60, 61]. Thus, further research is needed to relate fullerene accumulation in real organisms from quantitative methods in in-vitro studies.

\section{Conclusions}

This study provides a framework needed to develop a quantitative model for determination of the cellular uptake of fullerene which is critical for reducing toxicity and for improving the design of biomedical applications of this nanomaterial. In addition, this study is the first to identify the cellular transport mechanisms of unmodified fullerene by a quantitative approach. This study suggests that once fullerenes adsorbed on the cell surfaces, fullerenes can partly transport inside the cells by not only passive diffusion, but also active transport based on temperature dependence and reduced uptake in the presence of metabolic inhibitors. Endocytosis is an active transport which is mainly responsible for the nanoparticle uptake. There are several known pathways of endocytotic processes 
such as phagocytosis, pinocytosis, receptor-mediated endocytosis, and clathrin-mediated endocytosis [62]. Although this study suggested that microtubule-mediated pathways can be one transport process, further study can investigate the specific active transport mechanisms of fullerenes. In conclusion, this research suggests guidelines for developing quantitative methods for cellular uptake of other nanoparticles and provides a basis for future research related to active transport into environmental assessment protocols or monitoring tools for fullerenes. Furthermore, because the active transport mechanism directly depends on the cell type and function, the harmful effects of fullerene on different organs and species that have different cell membrane composition should be assessed, and this study's results provide a framework for such an evaluation.

\section{Nomenclature}

$\mathrm{C}_{60} \quad$ : Carbon fullerene

FBS : Fetal bovine serum

PBS : Phosphate buffer solution

TEM : Transmission electron microscopy

HPLC : High performance liquid chromatography

\section{Author Contributions}

Y.H. (Ph.D. student) conducted all the experiments and wrote the manuscript. X.W. (Ph.D. student) contributed to the method development and conducted a ANOVA test. H.M.L. (Professor) supervised the work and reviewed the manuscript. J.A.M. (Professor) supervised the work and reviewed the manuscript. L.E.K. (Professor) supervised the work and reviewed the manuscript.

\section{References}

1. Yong T, Zhang X, Bie N, et al. Tumor exosome-based nanoparticles are efficient drug carriers for chemotherapy. Nat. Commun. 2019;10:3838.

2. Li H, Wu X, Yang B, et al. Evaluation of biomimetically synthesized mesoporous silica nanoparticles as drug carriers: Structure, wettability, degradation, biocompatibility and brain distribution. Mater. Sci. Eng. C Mater. Biol. Appl. 2019;94:453-464.

3. Baghdan E, Pinnapireddy SR, Strehlow B, Engelhardt KH, Schafer J, Bakowsky U. Lipid coated chitosan-DNA nanoparticles for enhanced gene delivery. Int. J. Pharm. 2018;535: 473-479.

4. Choi SY, Jang SH, Park J, et al. Cellular uptake and cytotoxicity of positively charged chitosan gold nanoparticles in human lung adenocarcinoma cells. J. Nanopart. Res. 2012;14:1234.

5. Dou T, Wang J, Han C, Shao X, Zhang J, Lu W. Cellular uptake and transport characteristics of chitosan modified nanoparticles in Caco-2 cell monolayers. Int. J. Biol. Macromol. 2019;138: 791-799.

6. Chen Q, Yin D, Li J, Hu X. The effects of humic acid on the uptake and depuration of fullerene aqueous suspensions in two aquatic organisms. Environ. Toxicol. Chem. 2014;33:1090-1097.
7. Chithrani BD, Chan WC. Elucidating the mechanism of cellular uptake and removal of protein-coated gold nanoparticles of different sizes and shapes. Nano Lett. 2007;7:1542-1550.

8. Rancan F, Gao Q, Graf C, et al. Skin penetration and cellular uptake of amorphous silica nanoparticles with variable size, surface functionalization, and colloidal stability. ACS nano. 2012;6:6829-6842.

9. Jin H, Heller DA, Strano MS. Single-particle tracking of endocytosis and exocytosis of single-walled carbon nanotubes in NIH-3T3 cells. Nano Lett. 2008;8:1577-1585.

10. Sayes CM, Gobin AM, Ausman KD, Mendez J, West JL, Colvin VL. Nano-C60 cytotoxicity is due to lipid peroxidation. Biomaterials 2005;26:7587-7595.

11. Porter AE, Muller K, Skepper J, Midgley P, Welland M. Uptake of $\mathrm{C}_{60}$ by human monocyte macrophages, its localization and implications for toxicity: studied by high resolution electron microscopy and electron tomography. Acta Biomater. 2006;2: 409-419.

12. Cho M, Fortner JD, Hughes JB, Kim JH. Escherichia coli inactivation by water-soluble, ozonated C60 derivative: kinetics and mechanisms. Environ. Sci. Technol. 2009;43:7410-7415.

13. Lovern SB, Klaper R. Daphnia magna mortality when exposed to titanium dioxide and fullerene (C60) nanoparticles. Environ. Toxicol. Chem. 2006;25:1132-1137.

14. Foley S, Crowley C, Smaihi M. Cellular localisation of a water-soluble fullerene derivative. Biochem. Biophys Res. Commun. 2002;294:116-119.

15. Porter AE, Gass M, Muller K, Skepper JN, Midgley P, Welland $\mathrm{M}$. Visualizing the uptake of $\mathrm{C}_{60}$ to the cytoplasm and nucleus of human monocyte-derived macrophage cells using energy-filtered transmission electron microscopy and electron tomography. Environ. Sci. Technol. 2007;41:3012-3017.

16. Rouse JG, Yang J, Barron AR, Monteiro-Riviere NA. Fullerene-based amino acid nanoparticle interactions with human epidermal keratinocytes. Toxicol. In Vitro. 2006;20:1313-1320.

17. Cagle DW, Kennel SJ, Mirzadeh S, Alford JM, Wilson LJ. In vivo studies of fullerene-based materials using endohedral metallofullerene radiotracers. Proc. Natl. Acad. Sci. USA. 1999;96: 5182-5187.

18. Gulson B, Wong H. Stable isotopic tracing-a way forward for nanotechnology. Environ Health Perspect. 2006;114:1486-1488.

19. Pycke BF, Benn TM, Herckes P, Westerhoff P, Halden RU. Strategies for quantifying $\mathrm{C}_{60}$ fullerenes in environmental and biological samples and implications for studies in environmental health and ecotoxicology. TrAC Trends Anal. Chem. 2011;30:44-57.

20. Li W, Chen C, Ye C, et al. The translocation of fullerenic nanoparticles into lysosome via the pathway of clathrin-mediated endocytosis. Nanotechnology 2008;19:145102.

21. Franskevych D, Palyvoda K, Petukhov D, et al. Fullerene C 60 penetration into leukemic cells and its photoinduced cytotoxic effects. Nanoscale Res. Lett. 2017;12:40.

22. Pade V, Stavchansky S. Estimation of the relative contribution of the transcellular and paracellular pathway to the transport of passively absorbed drugs in the Caco-2 cell culture model. Pharm Res. 1997;14:1210-1215.

23. Hidalgo IJ, Borchardt RT. Transport of a large neutral amino 
acid (phenylalanine) in a human intestinal epithelial cell line: Caco-2. Biochim. Biophys. Acta. 1990;1028:25-30.

24. Sugano K, Kansy M, Artursson P. et al. Coexistence of passive and carrier-mediated processes in drug transport. Nat. Rev. Drug Discov. 2010;9:597-614.

25. Vasiluk L, Pinto LJ, Walji ZA. et al. Benzo[a]pyrene bioavailability from pristine soil and contaminated sediment assessed using two in vitro models. Environ. Toxicol. Chem. 2007;26: 387-393.

26. Buesen R, Mock M, Nau H, Seidel A, Jacob J, Lampen A. Human intestinal Caco-2 cells display active transport of benzo[a]pyrene metabolites. Chem. Biol. Interact. 2003;142:201-221.

27. Ma Z, Lim LY. Uptake of chitosan and associated insulin in Caco-2 cell monolayers: a comparison between chitosan molecules and chitosan nanoparticles. Pharm. Res. 2003;20:1812-1819.

28. Mao S, Germershaus O, Fischer D, Linn T, Schnepf R, Kissel T. Uptake and transport of PEG-graft-trimethyl-chitosan copolymer-insulin nanocomplexes by epithelial cells. Pharm. Res. 2005;22:2058-2068.

29. Win KY, Feng SS. Effects of particle size and surface coating on cellular uptake of polymeric nanoparticles for oral delivery of anticancer drugs. Biomaterials 2005;26:2713-2722.

30. Chen G, Lianqin Z, Fenghua Z, Fang Z, Mingming S, Kai H. Comparative evaluation of nano-CuO crossing Caco-2 cell monolayers and cellular uptake. J. Nanopart Res. 2015;17:195.

31. Xia XR, Monteiro-Riviere NA, Riviere JE. Trace analysis of fullerenes in biological samples by simplified liquid-liquid extraction and high-performance liquid chromatography. J. Chromatogr A. 2006;1129:216-222.

32. Petersen EJ, Henry TB. Methodological considerations for testing the ecotoxicity of carbon nanotubes and fullerenes: review. Environ. Toxicol. Chem. 2012;31:60-72.

33. Brant JA, Labille J, Bottero JY, Wiesner MR. Characterizing the impact of preparation method on fullerene cluster structure and chemistry. Langmuir 2006;22:3878-3885.

34. Ha Y, Liljestrand HM, Katz LE. Effects of lipid composition on partitioning of fullerene between water and lipid membranes. Water Sci. Technol. 2013;68:290-295.

35. Ha Y, Wang X, Liljestrand HM, Maynard JA, Katz LE. Bioavailability of Fullerene under Environmentally Relevant Conditions: Effects of Humic Acid and Fetal Bovine Serum on Accumulation in Lipid Bilayers and Cellular Uptake. Environ. Sci. Technol. 2016;50:6717-6727.

36. Ude VC, Brown DM, Viale L, Kanase N, Stone V, Johnston HJ. Impact of copper oxide nanomaterials on differentiated and undifferentiated Caco-2 intestinal epithelial cells; assessment of cytotoxicity, barrier integrity, cytokine production and nanomaterial penetration. Part Fibre Toxicol. 2017;14:31.

37. Vila L, García-Rodríguez A, Cortés C, et al. Effects of cerium oxide nanoparticles on differentiated/undifferentiated human intestinal Caco-2 cells. Chem. Biol. Interact. 2018;283:38-46.

38. Kennedy D, Qian H, Gies V, Yang L. Human serum albumin stabilizes aqueous silver nanoparticle suspensions and inhibits particle uptake by cells. Environ. Sci. Nano. 2018;5:863-867.

39. Lesniak A, Salvati A, Santos-Martinez MJ, Radomski MW, Dawson KA, Aberg C. Nanoparticle adhesion to the cell membrane and its effect on nanoparticle uptake efficiency. J. Am.
Chem. Soc. 2013;135:1438-1444.

40. Lesniak A, Fenaroli F, Monopoli MP, Aberg C, Dawson KA, Salvati A. Effects of the presence or absence of a protein corona on silica nanoparticle uptake and impact on cells. ACS nano. 2012;6:5845-5857.

41. Ha Y, Katz LE, Liljestrand HM. Distribution of Fullerene Nanoparticles between Water and Solid Supported Lipid Membranes: Thermodynamics and Effects of Membrane Composition on Distribution. Environ. Sci. Technol. 2015;49: 14546-14553.

42. Cho EC, Xie J, Wurm PA, Xia Y. Understanding the role of surface charges in cellular adsorption versus internalization by selectively removing gold nanoparticles on the cell surface with a $I_{2} / \mathrm{KI}$ etchant. Nano Lett. 2009;9:1080-1084.

43. Wilhelm C, Gazeau F, Roger J, Pons JN, Bacri JC. Interaction of anionic superparamagnetic nanoparticles with cells: Kinetic analyses of membrane adsorption and subsequent internalization. Langmuir 2002;18:8148-8155.

44. Ma X, Bouchard D. Formation of aqueous suspensions of fullerenes. Environ. Sci. Technol. 2009;43:330-336.

45. Labille J, Masion A, Ziarelli F, et al. Hydration and dispersion of $\mathrm{C}_{60}$ in aqueous systems: the nature of water-fullerene interactions. Langmuir 2009;25:11232-11235.

46. Dausend J, Musyanovych A, Dass M, et al. Uptake mechanism of oppositely charged fluorescent nanoparticles in HeLa cells. Macromol Biosci. 2008;8:1135-1143.

47. dos Santos T, Varela J, Lynch I, Salvati A, Dawson KA. Effects of transport inhibitors on the cellular uptake of carboxylated polystyrene nanoparticles in different cell lines. PloS one. 2011;6:e24438.

48. Lin IC, Liang M, Liu TY, Monteiro MJ, Toth I. Cellular transport pathways of polymer coated gold nanoparticles. Nanomed Nanotechnol. Biol. Med. 2012;8:8-11.

49. Gao X, Wang T, Wu B, et al. Quantum dots for tracking cellular transport of lectin-functionalized nanoparticles. Biochem. Biophys Res. Commun. 2008;377:35-40.

50. Sundara Rajan S, Vu TQ. Quantum dots monitor TrkA receptor dynamics in the interior of neural PC12 cells. Nano Lett. 2006;6:2049-2059.

51. Ruan G, Agrawal A, Marcus AI, Nie S. Imaging and tracking of tat peptide-conjugated quantum dots in living cells: new insights into nanoparticle uptake, intracellular transport, and vesicle shedding. J. Am. Chem. Soc. 2007;129:14759-14766.

52. Rejman J, Oberle V, Zuhorn IS, Hoekstra D. Size-dependent internalization of particles via the pathways of clathrin- and caveolae-mediated endocytosis. Biochem. J. 2004;377:159-169.

53. Kiss AL, Botos E. Endocytosis via caveolae: alternative pathway with distinct cellular compartments to avoid lysosomal degradation? J. Cell Mol. Med. 2009;13:1228-1237.

54. Qiao R, Roberts AP, Mount AS, Klaine SJ, Ke PCJNL. Translocation of C60 and its derivatives across a lipid bilayer. Nano Lett. 2007;7:614-619.

55. Bedrov D, Smith GD, Davande H, Li LJTJoPCB. Passive transport of C60 fullerenes through a lipid membrane: a molecular dynamics simulation study. J. Phys. Chem. B 2008;112:2078-2084.

56. Wong-Ekkabut J, Baoukina S, Triampo W, Tang I-M, Tieleman DP, Monticelli LJNn. Computer simulation study of fullerene 
translocation through lipid membranes. Nat. Nanotechnol. 2008;3:363.

57. Tao X, Fortner JD, Zhang B, He Y, Chen Y, Hughes JB. Effects of aqueous stable fullerene nanocrystals (nC60) on Daphnia magna: evaluation of sub-lethal reproductive responses and accumulation. Chemosphere 2009;77:1482-1487.

58. Tervonen K, Waissi G, Petersen EJ, Akkanen J, Kukkonen JV. Analysis of fullerene-C60 and kinetic measurements for its accumulation and depuration in Daphnia magna. Environ. Toxicol. Chem. 2010;29:1072-1078.

59. Oberdorster E, Zhu SQ, Blickley TM, McClellan-Green P, Haasch ML. Ecotoxicology of carbon-based engineered nanoparticles:
Effects of fullerene (C-60) on aquatic organisms. Carbon 2006;44:1112-1120.

60. Zhang X, Sun H, Zhang Z, Niu Q, Chen Y, Crittenden JC. Enhanced bioaccumulation of cadmium in carp in the presence of titanium dioxide nanoparticles. Chemosphere 2007;67:160-166.

61. Farkas J, Christian P, Gallego-Urrea JA, et al. Uptake and effects of manufactured silver nanoparticles in rainbow trout (Oncorhynchus mykiss) gill cells. Aquat. Toxicol. 2011;101: 117-125.

62. Feng Z, Ying Z, Ying L, et al. Cellular uptake, intracellular trafficking, and cytotoxicity of nanomaterials. Small 2011;7: 1322-1337. 